\title{
Calculation for Primary Combustion Characteristics of Boron-Based Fuel-Rich Propellant Based on BP Neural Network
}

\author{
Wu Wan'e and Zhu Zuoming \\ The Fifth Department, Xi'an Research Institute of Hi-Tech, Xi'an, Shaanxi 710025, China \\ Correspondence should be addressed to Wu Wan'e, wuwane@163.com
}

Received 29 July 2011; Revised 21 October 2011; Accepted 21 October 2011

Academic Editor: Constantine D. Rakopoulos

Copyright (๑) 2012 W. Wan'e and Z. Zuoming. This is an open access article distributed under the Creative Commons Attribution License, which permits unrestricted use, distribution, and reproduction in any medium, provided the original work is properly cited.

\begin{abstract}
A practical scheme for selecting characterization parameters of boron-based fuel-rich propellant formulation was put forward; a calculation model for primary combustion characteristics of boron-based fuel-rich propellant based on backpropagation neural network was established, validated, and then was used to predict primary combustion characteristics of boron-based fuel-rich propellant. The results show that the calculation error of burning rate is less than $\pm 7.3 \%$; in the formulation range (hydroxylterminated polybutadiene $28 \%-32 \%$, ammonium perchlorate $30 \%-35 \%$, magnalium alloy $4 \%-8 \%$, catocene $0 \%-5 \%$, and boron $30 \%)$, the variation of the calculation data is consistent with the experimental results.
\end{abstract}

\section{Introduction}

Boron-based fuel-rich propellant belongs to composite solid propellants and is used for solid rocket ramjet engine. The basic requirements of the propellant for the engine are high burning rate and appropriate pressure index at low pressure. In its combustion, there are multiphase physical and chemical reactions. The former low-pressure combustion model can only be used for qualitative analysis but not for simulation because many of the parameters cannot be measured by experiments, and thus primary combustion property research and formulation design are excessively dependent on experimental study [1-3]. Therefore, applying neural network to simulation of propellant combustion characteristics has become an important research direction, and, in recent years, the neural network method has been applied to HTPB composite solid propellant, NEPE propellant, and so forth [4-9]. But no public reports on the application of the method to calculation for primary combustion characteristics (burning rate and pressure index) of boron-based fuelrich propellant can be found at home and abroad. BP neural network model can achieve a very close approximation to a complex nonlinear function and is suitable to deal with those problems in which causal relationship is not clear, therefore, in this paper, the concrete combustion process is not taken into account, and calculation for primary combustion characteristics is realized by training BP neural network with formulations and corresponding burning rate data directly.

\section{Preferences of Propellant Formulation}

BP neural network is applied to calculation for primary combustion characteristics with inputs of pressure and characterization parameters of boron-based fuel-rich propellant formulation and output of corresponding burning rate; through training BP neural network, the complex function between input and output can be simulated; eventually, with the given pressure and propellant formulation, corresponding burning rate can be obtained. Therefore, selecting parameters which can reflect the characteristics of boronbased fuel-rich propellant formulation essentially is a top priority.

Based on the in-depth study of primary combustion characteristics of boron-based fuel-rich propellant [1-3], the main factors which can affect primary combustion characteristics are analyzed, and a practical scheme for selecting characterization parameters of boron-based fuel-rich propellant formulation was put forward. The characterization parameters are as follows. 
(1) HTPB content. HTPB (hydroxyl-terminated polybutadiene) is the flexible matrix of the propellant as well as an organic fuel, accounting for about $30 \%$ of the total mass of propellant.

(2) AP content. AP (ammonium perchlorate) is the only oxidant in the propellant, accounting for about $30 \%$ of the total mass of propellant.

(3) AP weight-average particle size. Weight-average particle size can reflect particle size gradation of AP. Selecting weight-average particle size as a characterization parameter can avoid setting out the different particle sizes and their corresponding content in the characterization parameters one by one, thereby reducing the number of the characterization parameters.

(4) B content. B (boron) is one of the main fuels in the propellant. Due to low primary combustion efficiency and propellant manufacturing problem brought by pure boron powder, coated boron, and reunion boron are usually adopted in current boron-based fuel-rich propellant. In the propellant formulation characterization, pure boron, coated boron and reunion boron must be separate. In addition, the type and amount of coating material in coated boron, the adhesive in reunion boron, and the particle size of reunion boron can also affect primary combustion characteristics of the propellant significantly; they should be characterized as parameters if necessary.

(5) Flammable metal content. In the propellant formulation characterization, $\mathrm{Mg}$ (magnesium), Al (aluminum), and MA (magnalium alloy) must be separate. In addition, the particle size of flammable metal can also affect primary combustion characteristics of the propellant; it should be characterized as a parameter if necessary.

(6) Burning rate catalyst content. The function of burning rate catalyst is to affect combustion characteristics of the propellant.

Besides, when other substances and factors in the propellant formulations can also affect primary combustion characteristics of the propellant, they should also be characterized as parameters if necessary. It should be highlighted that, in the simulation, characterization parameters of the propellant formulations should be selected according to actual needs and there is no need to use all the above parameters to characterize the propellant formulations. Selecting appropriate characterization parameters can greatly reduce the computing amount of neural network.

\section{Establishment and Validation of BP Neural Network Model}

Backpropagation is the generalization of the Widrow-Hoff learning rule to multiple-layer networks and nonlinear differentiable transfer functions. Input vectors and the corresponding target vectors are used to train a network until

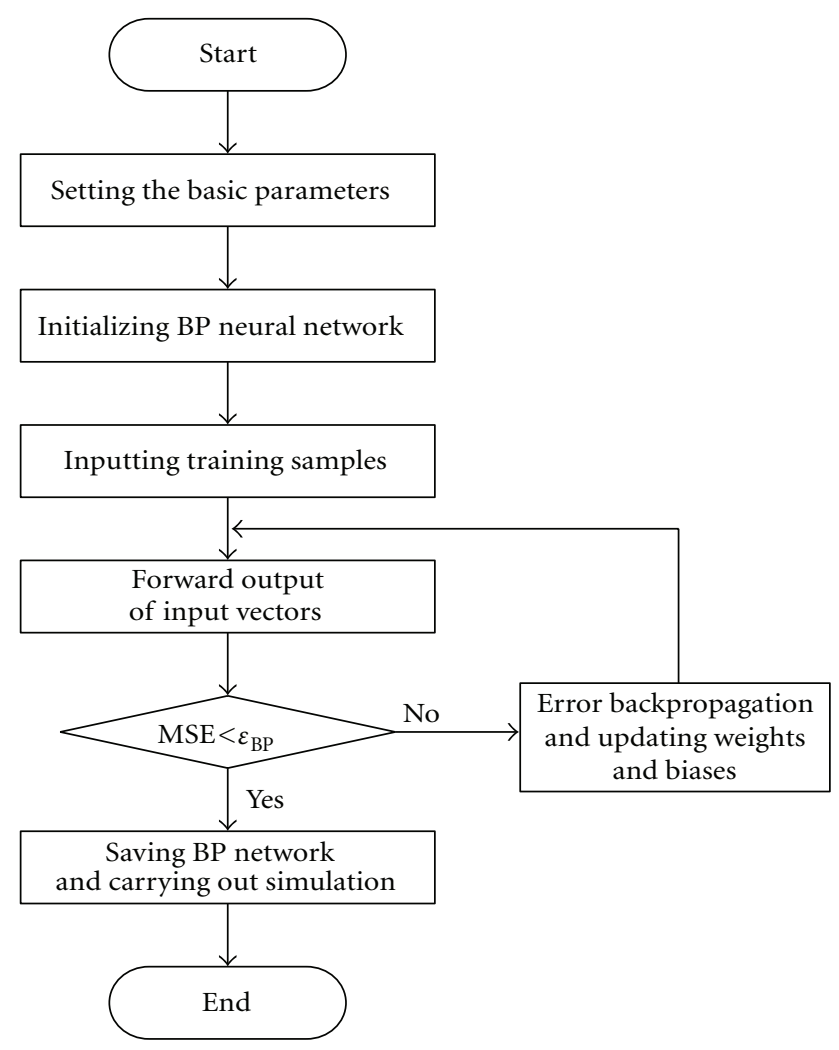

FIgURE 1: Computation flow chart of BP neural network.

it can approximate a function or associate input vectors with specific output vectors. Networks with biases, a sigmoid layer, and a linear output layer are capable of approximating any function with a finite number of discontinuities.

Standard backpropagation is a gradient descent algorithm, as is the Widrow-Hoff learning rule, in which the network weights are moved along the negative of the gradient of the performance function. The term backpropagation refers to the manner in which the gradient is computed for nonlinear multilayer networks.

Properly trained backpropagation networks tend to give reasonable answers when presented with inputs that they have never seen. Typically, a new input leads to an output, which is similar to that, the input vectors used in training lead to the correct output. This generalization property makes it possible to train a network on a representative set of input/target pairs and get good results without training the network on all possible input/output pairs [10].

Figure 1 shows the computing process of standard backpropagation neural network.

Kosmogorov's theorem shows that, with appropriate structure and weights-three-layer feedforward neural network can approximate any continuous function, so a threelayer structure is adopted in BP neural network model in this paper.

In order to overcome the shortcomings of $\mathrm{BP}$ neural network (easy falling into local optimum and slow convergence speed), gradient descent with momentum and adaptive learning rate backpropagation is adopted as learning 
TABLE 1: The detailed composition of 15 formulations adopted for simulation.

\begin{tabular}{lccccc}
\hline \multicolumn{2}{c}{ Number HTPB (\%) } & MA $(\%)$ & AP $(\%)$ & AP size $(\mathrm{mm})$ & GFP $(\%)$ \\
\hline 1 & 25 & 10 & 32 & 0.0944 & 3 \\
2 & 27 & 8 & 32 & 0.0944 & 3 \\
3 & 30 & 5 & 32 & 0.0944 & 3 \\
4 & 32 & 3 & 32 & 0.0944 & 3 \\
5 & 27 & 10 & 30 & 0.0944 & 3 \\
6 & 27 & 7 & 33 & 0.0944 & 3 \\
7 & 27 & 5 & 35 & 0.0944 & 3 \\
8 & 27 & 6 & 34 & 0.0803 & 3 \\
9 & 27 & 6 & 34 & 0.104 & 3 \\
10 & 27 & 6 & 34 & 0.127 & 3 \\
11 & 27 & 6 & 34 & 0.148 & 3 \\
12 & 30 & 8 & 32 & 0.0613 & 0 \\
13 & 28 & 8 & 32 & 0.0613 & 2 \\
14 & 27 & 8 & 32 & 0.0613 & 3 \\
15 & 25 & 8 & 32 & 0.0613 & 5 \\
\hline
\end{tabular}

algorithm of BP neural network. Momentum allows the network to ignore small features in the error surface. Without momentum, a network can get stuck in a shallow local minimum. With momentum, a network can slide through such a minimum. An adaptive learning rate attempts to keep the learning step size as large as possible while keeping learning stable. The learning rate is made responsive to the complexity of the local error surface.

In this paper, the experimental burning rate data of boron-based fuel-rich propellant in Chapter III of [3] are adopted for simulation. The propellant formulation is as follows: HTPB (hydroxyl-terminated polybutadiene) 28\%$32 \%$, AP (ammonium perchlorate) 30\%-35\%, MA (magnalium alloy, Mg-Al ratio of $1: 1$ ) 4\%-8\%, GFP (catocene) $0 \%-5 \%$, B (boron) $30 \%$. The detailed composition of 15 propellant formulations adopted for simulation is shown in Table 1. Accordingly, the following six parameters are selected as the training sample input:
(1) Pressure (MPa);
(2) HTPB content (\%);
(3) MA content (\%);
(4) AP content (\%);
(5) AP particle size (mm);
(6) GFP content (\%).

The corresponding output of the input sample composed of these six parameters is burning rate $(\mathrm{mm} / \mathrm{s})$.

Based on the previous design of BP neural network, a calculation model for primary combustion characteristics of boron-based fuel-rich propellant can be established. The setting of the basic parameters is shown in Table 2.

In 45 sets of burning rate data (15 propellant formulations at 3 pressures) adopted in this paper, 36 sets were
TABLE 2: The setting of the basic parameters of BP neural network model.

\begin{tabular}{lc}
\hline $\begin{array}{l}\text { Basic parameters of BP neural } \\
\text { network }\end{array}$ & Parameter setting \\
\hline $\begin{array}{l}\text { Structure } \\
\text { Transfer function }\end{array}$ & $\begin{array}{c}\text { Three-layer, 6-10-1 } \\
\text { tansig, purelin } \\
\text { Performance function } \\
\text { Mean square error of training } \\
\text { samples } \\
\text { Gradient descent with } \\
\text { Algorithm }\end{array}$ \\
$\begin{array}{l}\text { Momentum and adaptive } \\
\text { lnitial value of learning rate }\end{array}$ & 0.9 \\
Ratio to increase learning rate & 0.05 \\
Ratio to decrease learning rate & 1.05 \\
Maximum performance & 0.7 \\
increase & 1.04 \\
Performance goal & 0.001 \\
Maximum number of epochs & 5000 \\
to train &
\end{tabular}

selected as training samples and 9 sets as validation samples. First, use training samples to train BP neural network 10 times, respectively, and save corresponding network one by one; then use validation samples to validate these neural networks.

The network which has the minimum mean square error of validation samples was saved as the calculation model for primary combustion characteristics and used to calculate burning rate of 15 experimental formulations under three different pressures. The comparison between calculated data and tested data showed that in 45 sets of data, 35 sets' relative deviation were within $\pm 3 \%$, accounting for $77.8 \%$; 8 sets' relative deviation were more than $\pm 3 \%$ and less than $\pm 5 \%$, accounting for $17.8 \%$; only 2 sets' relative deviation were more than $\pm 5 \%$, accounting for $4.4 \%$; all the data's relative deviation were within $\pm 7.3 \%$; 9 sets of validation sample data's relative deviation were totally within $\pm 5 \%$. This shows that BP neural network model has rather high calculation accuracy and it can meet the need of calculation for primary combustion characteristics.

To validate further accuracy and effectiveness of BP neural network model, multiple linear regression (MLR), radial basis network (RBF), and generalized regression neural network (GRNN) are adopted to calculation based on the same samples and compared with BP neural network model. Table 3 shows mean square error comparison among the four calculation models.

As can be seen in Table 3, compared with the other three calculation models, BP neural network model has the highest accuracy. This is the advantage of BP neural network model.

Besides, it should be highlighted that, in the simulation, if more data at more pressure levels can be used to train the network model, the calculation accuracy usually can be further improved. 
TABLE 3: Mean square error comparison among the four calculation models.

\begin{tabular}{lcc}
\hline $\begin{array}{l}\text { Calculation } \\
\text { model }\end{array}$ & $\begin{array}{c}\text { Mean square error of } \\
\text { training samples }\end{array}$ & $\begin{array}{c}\text { Mean square error of } \\
\text { validation samples }\end{array}$ \\
\hline $\begin{array}{l}\text { BP neural } \\
\text { network }\end{array}$ & 0.0058 & 0.0152 \\
MLR & 0.2826 & 0.2917 \\
RBF & $3.115 \times 10^{-5}$ & 0.0393 \\
GRNN & 0.0039 & 0.0322 \\
\hline
\end{tabular}

\section{Prediction of Primary Combustion Characteristics of Boron-Based Fuel-Rich Propellant}

In this paper, based on the established BP neural network model, in the pressure range $(0.5-1.5 \mathrm{MPa})$ and in the formulation range (HTPB 28\%-32\%, AP 30\%-35\%, MA $4 \%-8 \%$, GFP $0 \%-5 \%$, and B 30\%), primary combustion characteristics of boron-based fuel-rich propellant were predicted, and the variation was preliminarily summed up. The following burning rate data were obtained by BP neural network model, and the pressure index data were obtained by fitting of the burning rate data under different pressures with the empirical equation listed as follows:

$$
r_{p}=b P^{n}
$$

In (1), $r_{P}$ refers to burning rate at some pressure; $P$ refers to pressure; $n$ refers to pressure index.

When the total amount of HTPB/MA is fixed, effect of HTPB content (wt $\%$ ) on burning rate and pressure index can be shown in Figures 2(a) and 2(b), respectively. In Figures 2-5, C represents calculation data and E represents experimental data. It can be seen that when increasing HTPB content with a corresponding reduction in MA content, burning rate (under a certain pressure) decreases; pressure index first increases, then decreases and finally rises slightly.

When the total amount of AP/MA and AP particle size are fixed, effect of AP content (wt\%) on burning rate and pressure index can be shown in Figures 3(a) and 3(b), respectively. It can be seen that when increasing AP content with a corresponding reduction in MA content, both burning rate (under a certain pressure) and pressure index increase.

When AP content is fixed, effect of AP particle size on burning rate and pressure index can be shown in Figures 4(a) and 4(b), respectively. It can be seen that when increasing AP particle size, burning rate (under a certain pressure) decreases; pressure index first increases and then decreases.

When the total amount of GFP/HTPB is fixed, effect of GFP content (wt $\%$ ) on burning rate and pressure index can be shown in Figures 5(a), and 5(b), respectively. It can be seen that when increasing GFP content with a corresponding reduction in HTPB content, both burning rate (under a certain pressure) and pressure index increase.

In addition, it can be seen from Figures $2-5$ that the variation of the calculation data tallies well with experimental results, which validates further accuracy and effectiveness of

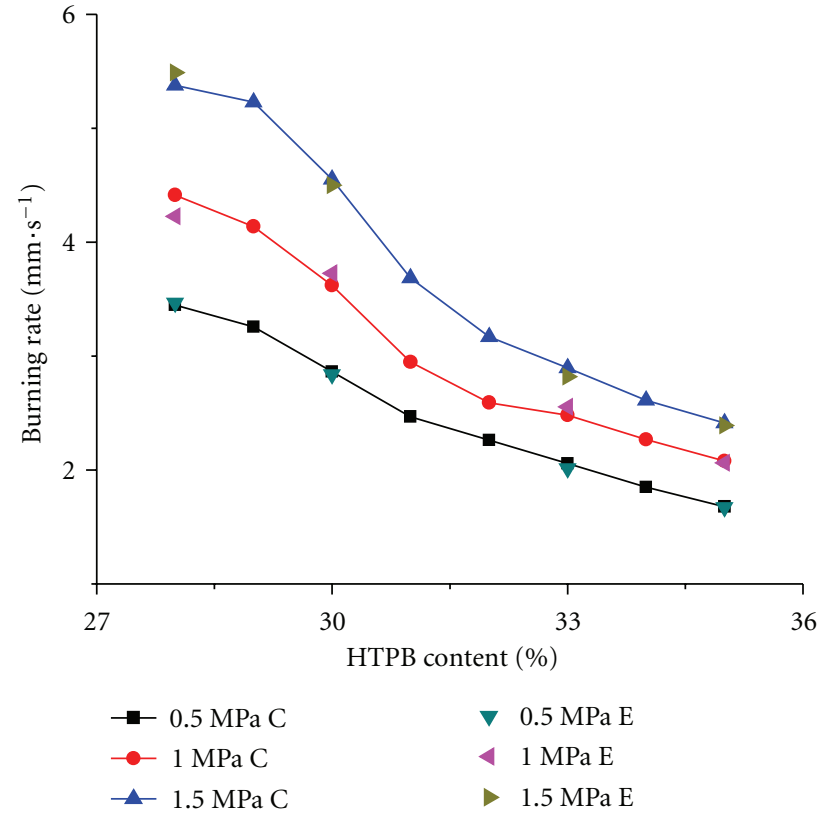

(a)

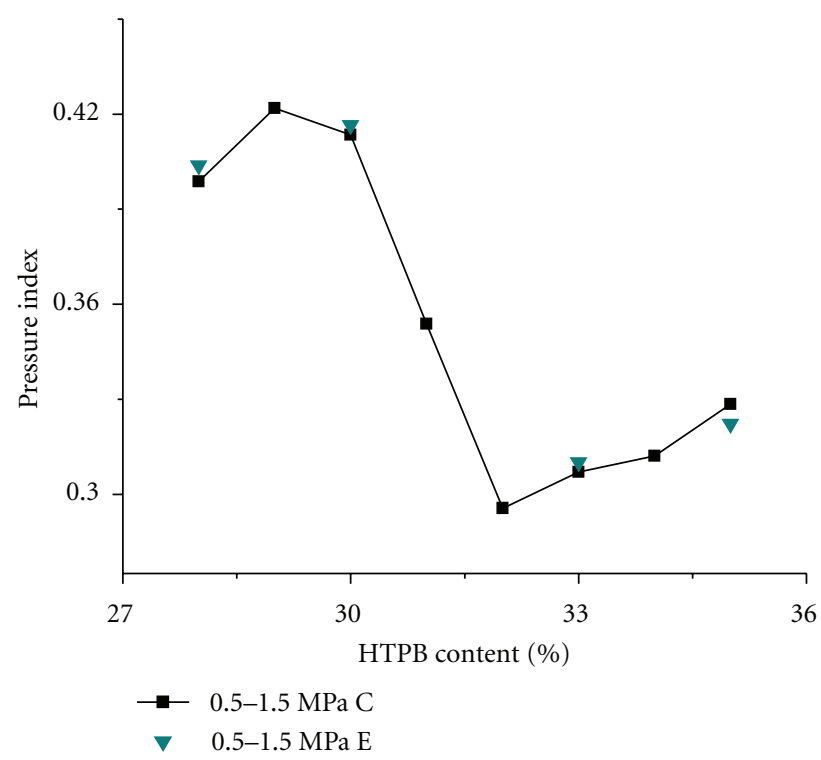

(b)

Figure 2: Effect of HTPB content (wt $\%$ ) on burning rate (a) and pressure index (b).

BP neural network model. Furthermore, BP neural network model can simulate burning rate and pressure index of propellant formulations not tested by experiments, which makes important sense in combustion property researches and formulation design of boron-based fuel-rich propellant.

\section{Conclusions}

(1) In this paper, a calculation model for primary combustion characteristics of boron-based fuel-rich 


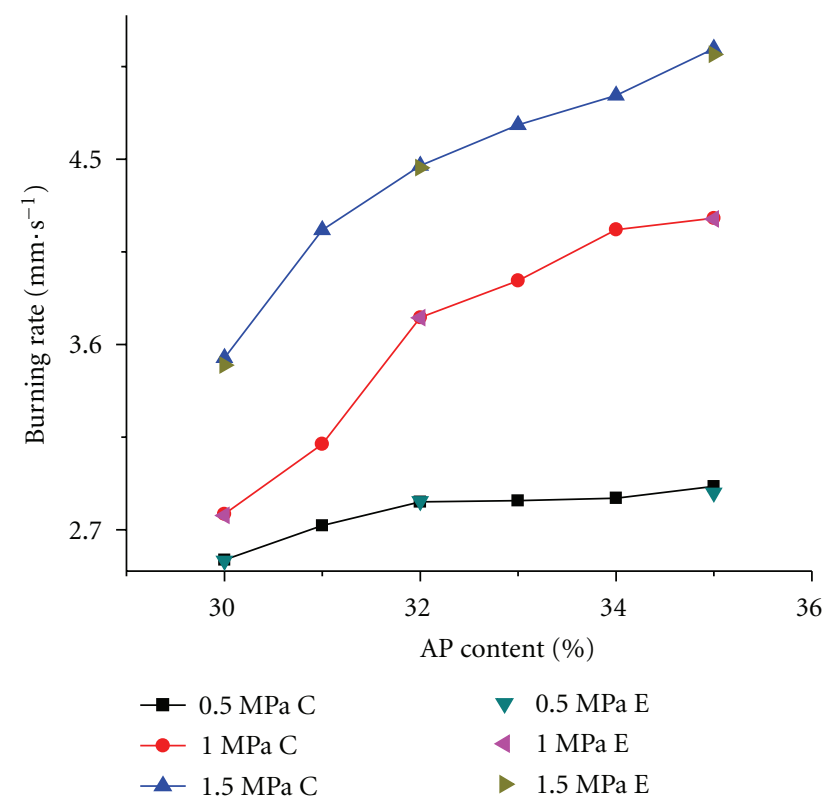

(a)

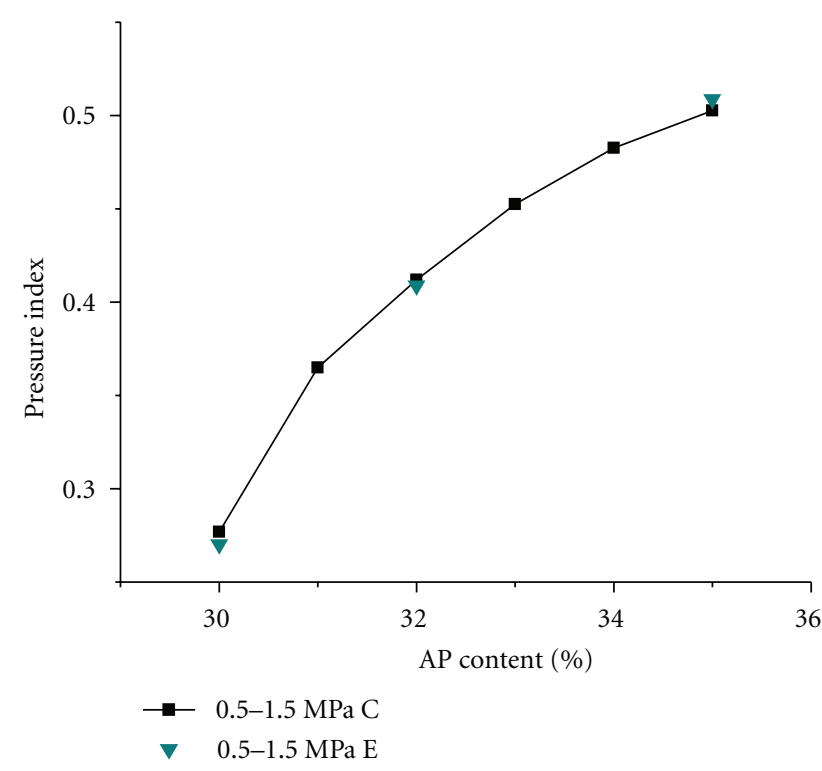

(b)

FIgURE 3: Effect of AP content (wt\%) on burning rate (a) and pressure index (b).

propellant based on BP neural network was established. The simulation results showed that, BP neural network model is superior to multiple linear regression, radial basis network, and generalized regression neural network; the relative deviation of $95.6 \%$ of the calculation data obtained by using BP neural network model was less than $\pm 5 \%$, and all the calculation data's relative deviation was within $\pm 7.3 \%$.

(2) The established BP neural network model was used to predict primary combustion characteristics of

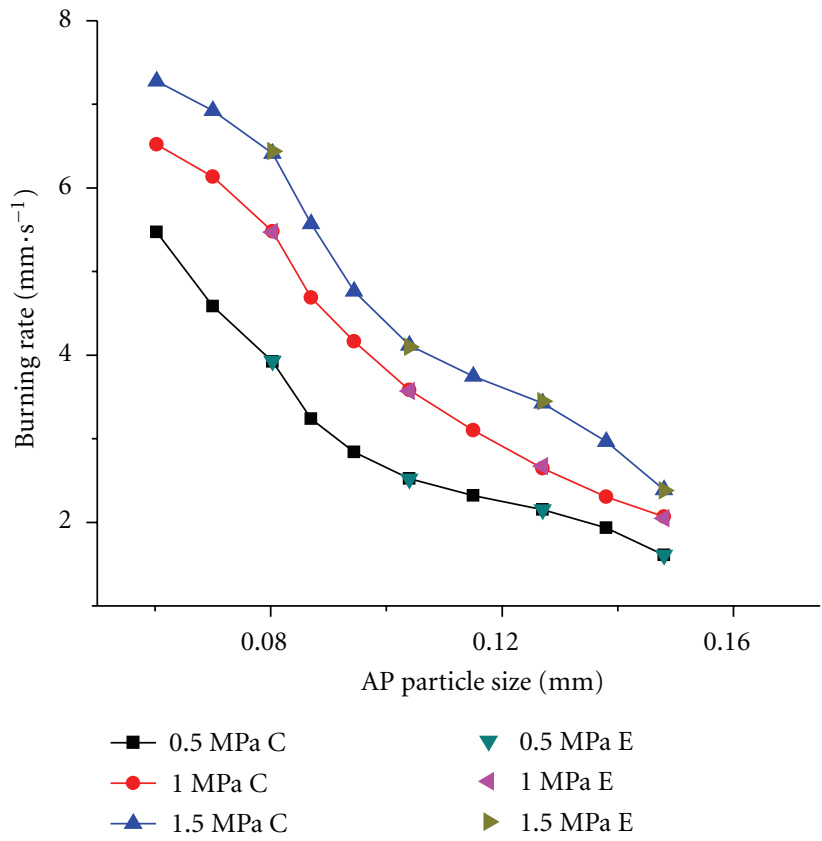

(a)

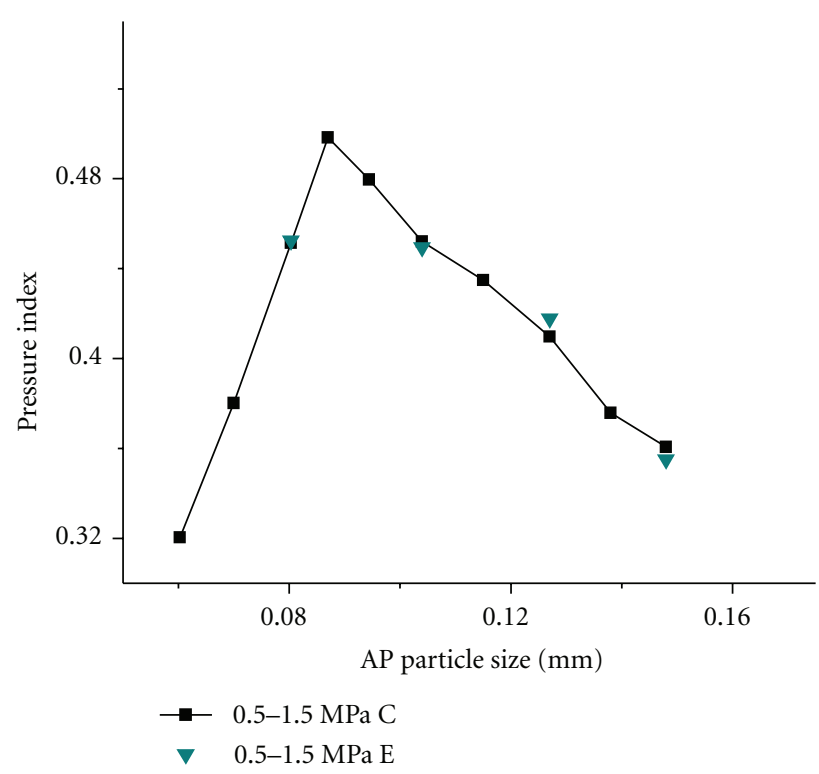

(b)

FIGURE 4: Effect of AP particle size on burning rate (a) and pressure index (b).

boron-based fuel-rich propellant. HTPB content, AP content, AP particle size, and GFP content in the propellant formulation were changed, and burning rate and pressure index of corresponding formulations were calculated. The results showed that the variation was consistent with the experimental results.

(3) In the adjustable formulation range, the calculation results of different formulations under different pressures can be directly used to optimize the design of 


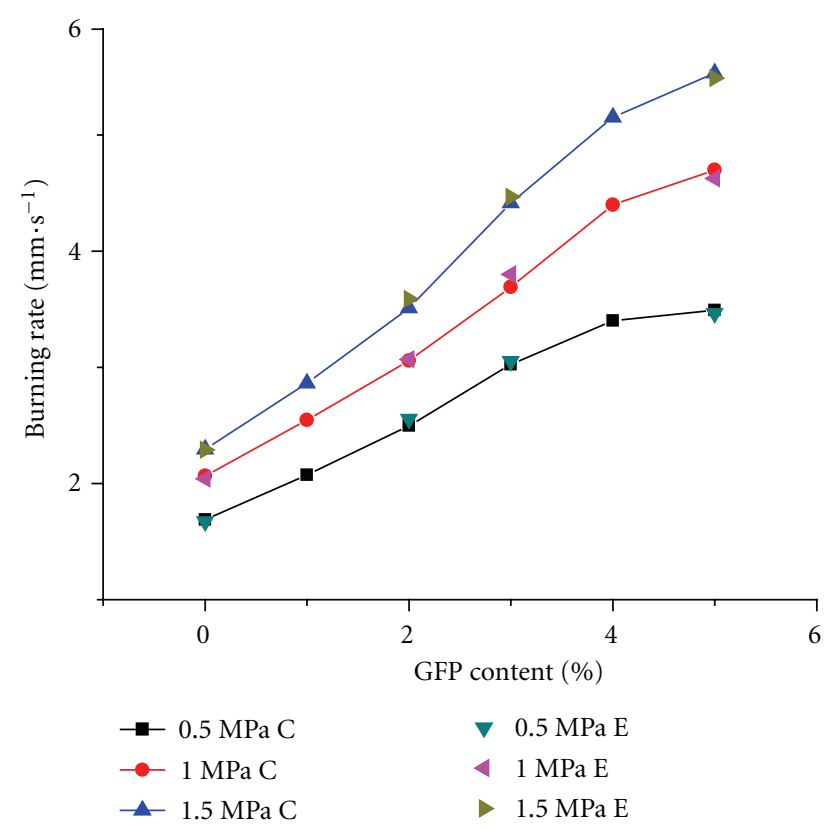

(a)

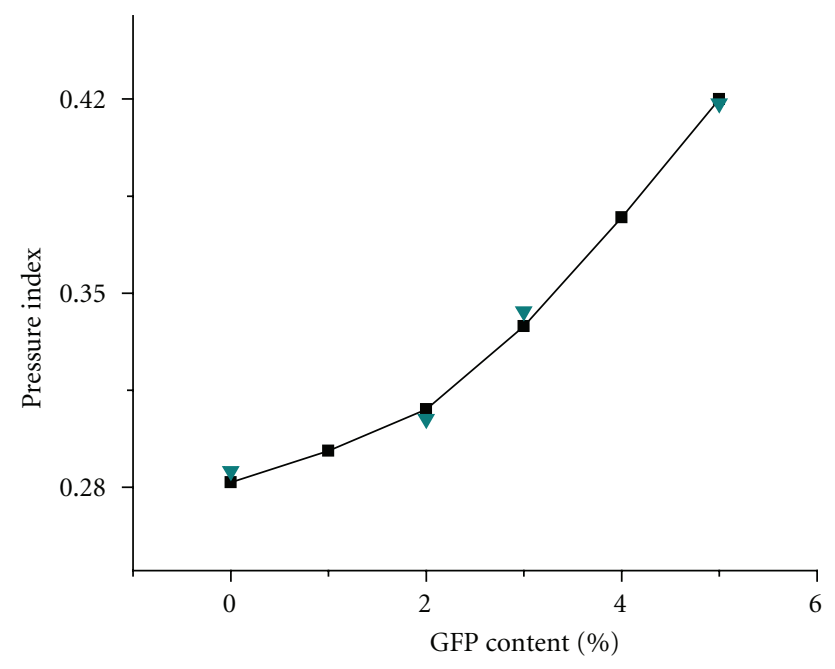

$\rightarrow 0.5-1.5 \mathrm{MPaC}$

$\nabla \quad 0.5-1.5 \mathrm{MPa} \mathrm{E}$

(b)

Figure 5: Effect of GFP content (wt\%) on burning rate (a) and pressure index (b).

propellant formulations, which can reduce the experimental workload, shorten the research cycle, and improve reproducibility of the research.

\section{References}

[1] H. Songqi, Study on primary combustion of boron-based fuelrich propellant, Ph.D. thesis, Northwestern Polytechnical University, Xi'an, China, 2004.

[2] W. Yinghong, Researches on combustion of boron-based fuelrich solid propellants in lower pressure, Ph.D. thesis, Northwestern Polytechnical University, Xi'an, China, 2004.
[3] W. Wan'e, Researches on mechanism of pressure index increase of boron-based fuel-rich propellant, Ph.D. thesis, Northwestern Polytechnical University, Xi'an, China, 2009.

[4] P. Deng, D. Tian, and F. Zhuang, "A neural network for modeling calculations for composite propellants," Journal of Propulsion Technology, vol. 17, no. 4, pp. 69-76, 1996 (Chinese).

[5] G. Baohua, P. Baolin, and W. Guangtian, "Application of artificial neural network in predicting mechanical property of HTPB propellant," Journal of Solid Rocket Technology, vol. 20, no. 1, pp. 51-56, 1997 (Chinese).

[6] P.-J. Liu, X. Lu, and G.-Q. He, "Burning rate relativity investigation using artificial neural network," Journal of Propulsion Technology, vol. 25, no. 2, pp. 156-158, 2004 (Chinese).

[7] L. Jianmin, T. Shaochun, X. Fuming et al., "Prediction of burning rate of HTPB propellant by artificial neural network model," Chinese Journal of Explosives and Propellants, vol. 29, no. 3, pp. 13-16, 2006 (Chinese).

[8] H. Yongjun and L. Jinxian, "Burning rate relativity investigation using BP neural network based on genetic algorithm," Journal of Projectiles Rockets Missiles and Guidance, vol. 26, no. 1, pp. 144-146, 2006 (Chinese).

[9] X.-P. Zhang and Z.-L. Dai, "Calculation for high-pressure combustion properties of high-energy solid propellant based on GA-BP neural network," Journal of Solid Rocket Technology, vol. 30, no. 3, pp. 229-232, 2007.

[10] M. T. Hagan, H. B Demuth, and M. Beale, Neural Network Design, PWS Publishing Company, 1996. 

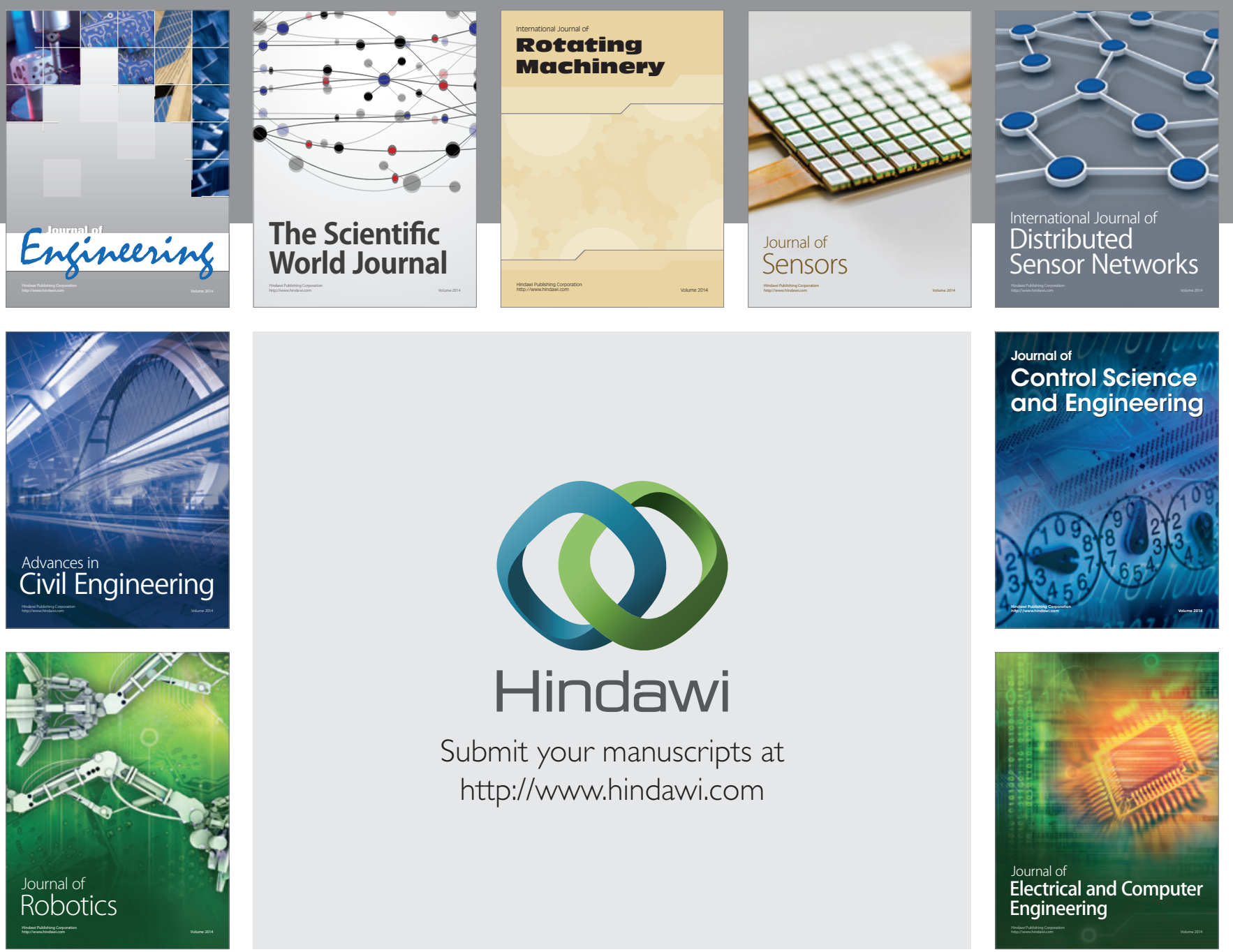

Submit your manuscripts at

http://www.hindawi.com
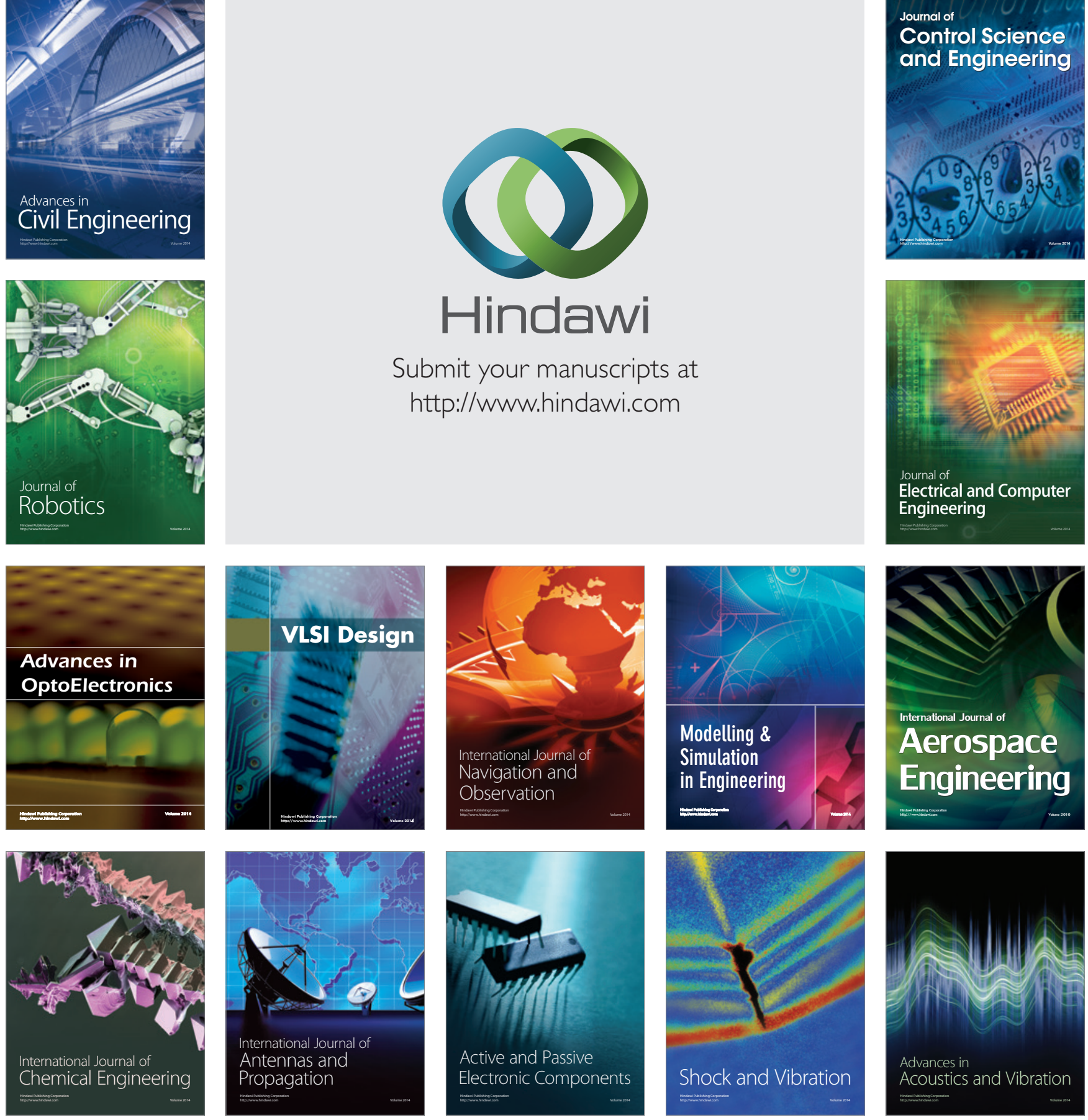